\title{
Effect of the methacrylate-based endodontic sealer Epiphany on rat peritoneal macrophages viability
}

\author{
Jenifer Martín-González ${ }^{1}$, Lizett Castellanos-Cosano ${ }^{1}$, Francisco Javier López-Frías ${ }^{2}$, Benito Sánchez-Do- \\ mínguez $^{1}$, Cristina Calvo-Monroy ${ }^{1}$, Luis Oscar Alonso-Ezpeleta ${ }^{3}$, Juan José Segura-Egea ${ }^{4}$ \\ ${ }^{1}$ Doctoral fellow, Department of Stomatology, School of Dentistry, University of Sevilla, C/ Avicena s/n, 41009-Sevilla, Spain. \\ ${ }^{2}$ Associated Professor, Department of Endodontics, School of Dentistry, University of Sevilla, C/ Avicena s/n, 41009-Sevilla, \\ Spain. \\ ${ }^{3}$ Associated Professor, Department of Endodontics, School of Dentistry, University of Zaragoza, 22006-Huesca, Spain. \\ ${ }^{4}$ Professor, Department of Endodontics, School of Dentistry, University of Sevilla, C/ Avicena s/n, 41009-Sevilla, Spain.
}

Correspondence:

Dpto. de Estomatología,

Facultad de Odontología,

C/Avicena s/n, 41009-Seville (SPAIN)

E-mail:segurajj@us.es

\author{
Martín-González J, Castellanos-Cosano L, López-Frías FJ, Sánchez-Do- \\ mínguez B, Calvo-Monroy C, Alonso-Ezpeleta LO, Segura-Egea JJ. Effect \\ of the methacrylate-based endodontic sealer Epiphany on rat peritoneal \\ macrophages viability. J Clin Exp Dent. 2011;3(3):e216-21. \\ http://www.medicinaoral.com/odo/volumenes/v3i3/jcedv3i3p216.pdf

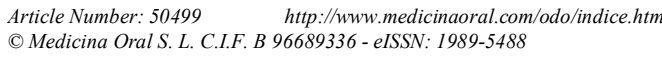

\begin{abstract}
Objective: To evaluate the effect of the endodontic sealer Epiphany on rat peritoneal macrophages viability. Materials and methods: Peritoneal macrophages were obtained from Wistar rats and resuspended in RPMI1640 medium. Undiluted (crude extract) and diluted extracts to $10 \%, 1 \%, 0.1 \%, 0.01 \%, 0.001 \%$ and $0.0001 \%$ of Epiphany, AH 26 and AH Plus sealers on RPMI-1640 medium were tested for cytotoxicity to rat peritoneal macrophages using the trypan blue dye exclusion assay. Data were analyzed statistically by the Kruskal-Wallis and Mann-Whitney tests at 5\% significance level.

Results: Crude extract of Epiphany killed 51\% of cells, but was less cytotoxic that crude extracts of AH Plus and AH 26, which killed $81 \%$ and $86 \%$ of cells, respectively. Ten-fold dilutions of Epiphany, AH Plus and AH 26 killed $44 \%, 56 \%, 62 \%$ of macrophages, respectively. A hundred dilution of Epiphany only killed $7 \%$ of macrophages, but the same dilution of AH Plus and AH 26 killed 10\% and 31\% of macrophages, respectively. Lower dilutions of sealer extracts caused minimal cell death as compared to the control groups $(\mathrm{p}>0.05)$.

Conclusions: The methacrylate-based endodontic sealer Epiphany showed lower cytotoxicity on macrophages than resin-based sealers AH Plus and AH 26. Dilution of elutes of the three materials by tenfold markedly reduced their effects.
\end{abstract}

Key Words: Endodontic sealers, Cytotoxicity, Epoxy-resin based materials, Methacrylate based materials, Periapical immune reaction. 


\section{Introduction}

Successful endodontic therapy depends on thorough cleaning and shaping followed by obturation of the root canal system. During obturation, root canal sealers serve to fill irregularities between the dentinal walls and the gutta-percha core, act as lubricants, fill lateral or accessory canals, and bond to gutta-percha and dentin. Endodontic sealers must be able to eliminate or minimize the ingress or egress of bacteria and their byproducts (1). Root filling materials are placed in close contact with the periapical tissues for extended periods of time, and as a result, elutable substances or degradation products from root canal fillings might gain access to surrounding tissues (periodontal ligaments, alveolar bone) through numerous connections, e.g. dentinal tubules, accessory and lateral canals, and apical foramina. The tissue response to these materials may influence the final outcome of the root canal treatment (2). A sealer should not hinder tissue repair, but have a favorable tissue response that promotes healing of the periapical tissues stimulating the reorganization of injured structures. So, it is required that these materials are neither cytotoxic, genotoxic, mutagenic nor associated with any other negative biologic effects.

Previous studies have shown that the biocompatibility of different material classes and products of root canal sealers vary considerably (3-6). AH 26 and AH Plus (Dentsply DeTrey, GmbH, Konstanz, Germany) are two of the most commonly used epoxy resin-based endodontic sealers (7). In the last years, methacrylate based endodontic sealers have been developed. Epiphany (Pentron Clinical Technologies, Wallingford, CT, USA) is a methacrylate based dual curable resin composite sealer used with Resilon, a thermoplastic synthetic polymer (polyester)- based core filling material. It has been suggested that the sealer bonds to both the root canal dentin wall and the Resilon core, forming a "monoblock" system within the root canal (8). It is reasonable to assume that endodontic sealers, following their leakage through dentinal tubules, accessory and lateral canals, and apical foramina, may affect the viability of periradicular macrophages. The aim of this in vitro study was to study the effect of the methacrylate based sealer Epiphany on rat peritoneal macrophages viability measured by trypan blue dye exclusion assay.

\section{Materials and Methods}

\section{Collection of rat peritoneal macrophages}

The Ethics Committee approved thestudy. Peritoneal macrophages were elicited from Wistar rats as described previously (5). Briefly, each rat was injected intraperitoneally with $5 \mathrm{ml}$ of sterile $6 \%$ sodium caseinate. Animals were killed after 4 days by decapitation and the peritoneal cavity was washed with $10 \mathrm{ml}$ of cold $0.9 \% \mathrm{NaCl}$ (Sigma Chemical, St. Louis, MO, USA). After a 2 min massage, the cell exudate was removed with a syringe and centrifuged for $10 \mathrm{~min}$ at $250 \mathrm{xg}$ at $4^{\circ} \mathrm{C}$. The contaminating red blood cells were lysed with cold $0.2 \% \mathrm{NaCl}$. The remaining cells were then washed with $0.9 \% \mathrm{NaCl}$ by centrifugation, resuspended in RPMI-1640 medium (Sigma Chemical, St. Louis, MO, USA), counted, adjusted in the same medium at 2-4 $\times 10^{6}$ macrophages $/ \mathrm{ml}$ and used immediately for experiments. Mean cells per rat varied from 20-30 x 10 which $85 \%$ to $95 \%$ were macrophages by morphological criteria in Giemsa and Papanicolaou staining techniques.

Endodontic sealer extracts preparation

Table 1 shows the tested materials and their compositions.

\begin{tabular}{|c|c|c|c|}
\hline Product & Material type & Manufacturer & Composition \\
\hline AH 26 & Epoxi-resin based & $\begin{array}{l}\text { Dentsply DeTrey } \\
\text { GmbH, Konstanz, } \\
\text { Germany }\end{array}$ & $\begin{array}{l}\text { Component A } \\
\text { Silver powder } \\
\text { Bismuth oxide } \\
\text { Hexamethylenetetramine } \\
\text { Titan (IV)-oxide } \\
\text { Component B } \\
\text { Epoxybisphenol (liquid) }\end{array}$ \\
\hline AH PLUS & Epoxi-resin based & $\begin{array}{l}\text { Dentsply DeTrey } \\
\text { GmbH, Konstanz, } \\
\text { Germany }\end{array}$ & $\begin{array}{l}\text { Component } \mathbf{A} \\
\text { Epoxy resins } \\
\text { Calcium tungstate } \\
\text { Zirconium oxide } \\
\text { Silica } \\
\text { Iron oxide pigments Component B } \\
\text { Amines } \\
\text { Calcium tungstate } \\
\text { Zirconium oxide } \\
\text { Silica } \\
\text { Silicone oil }\end{array}$ \\
\hline Epiphany & Multi-methacrylates & $\begin{array}{l}\text { Pentron Clinical } \\
\text { Technologies, LLC, } \\
\text { Wallingford, CT, USA }\end{array}$ & $\begin{array}{l}\text { Sealer: Bis-GMA, ethoxylated Bis- } \\
\text { GMA } \\
\text { UDMA, hydrophilic monomers } \\
\text { Thinning resin: EBPADMA resins } \\
\text { with photo initiator, amines, stabilizer. }\end{array}$ \\
\hline
\end{tabular}

Table 1. 
The sealers were mixed according to the manufacturer's instructions under aseptic conditions. One gram of each of the mixed materials was then dispensed into one well of a 6-well tissue culture plate. The materials were covered with $10 \mathrm{~mL}$ of sterile RPMI-1640 medium and eluted for 1 week at $37^{\circ} \mathrm{C}$. After 1 week, the plates were removed from the incubator and the elutes were centrifuged at 750 $\mathrm{x} g$ for $1 \mathrm{~min}$ to remove any solid particles. These elutes (crude extracts) were then used for cytotoxicity testing by trypan blue (Sigma Chemical, St Louis, MO, USA) dye exclusion assay. Serial dilutions from the crude extract $(100 \%)$ were made to obtain dilutions of $10 \%, 1 \%, 0.1 \%$, $0.01 \%, 0.001 \%$, and $0.0001 \%$ in RPMI medium. Media alone stored under the same conditions were used as negative controls.
Assay of macrophages viability

Aliquots of $180 \mu \mathrm{l}$ of cell suspension, adjusted in RPMI 1640 medium at 2-4 x $10^{6}$ cells $/ \mathrm{ml}$, were dispensed in Eppendorf tubes. Crude extract or dilutions of endodontic sealer, AH 26, AH Plus or Epiphany, was added (20 $\mu \mathrm{l})$. Medium alone $(20 \mu \mathrm{l})$ was added instead of endodontic sealer to control samples. To test the effect of crude extracts of the endodontic sealers, cell suspension was adjusted in undiluted extracts at 2-4 x $10^{6}$.

After incubation for $15 \mathrm{~min}$ at $37^{\circ} \mathrm{C}$ in a humidified atmosphere of $5 \% \mathrm{CO} 2$, the reaction was stopped and the effect of the different materials on rat peritoneal macrophages was evaluated by $0.2 \%$ (final concentration) trypan blue dye exclusion analysis. Blue coloured cells were considered to be nonviable. Briefly, the cell number was

\begin{tabular}{ll}
\hline Substance & Dilution \\
\hline Control & --- \\
AH 26 & $0.0001 \%$ \\
AH 26 & $0.001 \%$ \\
AH 26 & $0.01 \%$ \\
AH 26 & $0.1 \%$ \\
AH 26 & $1 \%$ \\
AH 26 & $10 \%$ \\
AH 26 & $100 \%$
\end{tabular}

$\begin{array}{ll}\text { AH Plus } & 0.0001 \% \\ \text { AH Plus } & 0.001 \% \\ \text { AH Plus } & 0.01 \% \\ \text { AH Plus } & 0.1 \% \\ \text { AH Plus } & 1 \% \\ \text { AH Plus } & 10 \% \\ \text { AH Plus } & 100 \%\end{array}$

$\begin{array}{ll}\text { Epiphany } & 0.0001 \% \\ \text { Epiphany } & 0.001 \% \\ \text { Epiphany } & 0.01 \% \\ \text { Epiphany } & 0.1 \% \\ \text { Epiphany } & 1 \% \\ \text { Epiphany } & 10 \% \\ \text { Epiphany } & 100 \%\end{array}$

$96.3 \pm 8.6 \%$
$92.1 \pm 7.2 \%$
$94.7 \pm 6.4 \%$
$95.9 \pm 7.8 \%$
$92.8 \pm 6.3 \%$
$56.2 \pm 4.8 \%$
$48.6 \pm 5.8 \%$

$>0.05$

$>0.05$

$>0.05$

$>0.05$

$>0.05$

$<0.01$

$<0.01$

Table 2. Effect of the methacrylate based sealer Epiphany and the epoxy-resin based sealers AH 26 and AH Plus on rat peritoneal macrophages viability by trypan blue dye exclusion assay expressed as percentage of viable cells. Values are the mean \pm SEM of eight separate experiments performed in triplicate. 
determined by counting the viable cells in a hemocytometer. The percentage of viable cells from each well after incubation with material extracts was obtained by applying the following equation: \% viable cells $=(\mathrm{VC} / \mathrm{TC}) \mathrm{X}$ 100 , where $\mathrm{VC}=$ viable cells counted and $\mathrm{TC}=$ total cells counted (stained plus unstained cells).

Statistical analysis

All values were expressed as the mean $\pm \mathrm{SEM}$ of the number of experiments (eight), performed in triplicate. The difference between the control and experimental groups was analyzed statistically by the Kruskal-Wallis and MannWhitney tests (SPSS version 10.0; SPSS Inc. Chicago, IL, USA). A p-value $<0.05$ was considered statistically significant.

\section{Results}

The effect of the methacrylate based endodontic sealer Epiphany and the epoxy-resin sealers AH 26 and AH Plus on rat peritoneal macrophages viability by trypan blue dye exclusion assay are shown in Table 2 expressed as percentage of viable cells. Crude and $10 \%$ extracts of the three sealers reduced significantly cell viability when compared to the control groups $(\mathrm{p}<0.05)$. The extract of AH 26 at $1 \%$ also caused a significant reduction of macrophages viability $(\mathrm{p}<0.05)$. Crude extracts of Epiphany, AH Plus and AH 26 killed 51\%, 81\%, and 86\% of cells, respectively. Ten-fold dilutions of Epiphany, AH Plus and AH 26 and killed $44 \%, 56 \%$ and $62 \%$ of macrophages, respectively. A hundred dilution of Epiphany killed 7\% of cells, but the same dilution of AH Plus and AH 26 killed 10\% and 31\% of macrophages, respectively. Lower dilutions of sealer extracts caused minimal cell death as compared to the control groups ( $\mathrm{p}>0.05)$.

\section{Discussion}

Extrusion of endodontic sealers beyond the apical foramen is undesirable because involve direct contact of the sealer with periapical tissues altering the inflammatory and reparative processes. This makes relevant to study the effects of the sealers on immune cells and their cytotoxicity: to avoid unwanted side effects following the use of canal sealers, which is important for the clinical outcome, only materials exerting minimum deleterious effects on living cells should be used(4).

Root canal sealers cytotoxicity can be studied in vitro by means of several tests, being trypan blue dye exclusion assay chosen for the present study because it is easy to perform and allows for distinguishing non-viable from viable cells by microscopic analysis (9). Trypan blue staining of non-viable cells is a common procedure used in cell culture research, and it relies on the premise that vital cells will not allow the stain to penetrate through cell membranes (10). The accuracy of trypan blue in distinguishing vital and non-vital cells has been verified using scanning electron microscopic (11). These authors showed that cells permeated by the stain (non-vital cells) presented disruption of organelles, whereas vital cells presented integrity of membranes and organelles, as confirmed by ultra structural analysis. Trypan blue dye exclusion assay has been used by others investigators to evaluate the cytotoxic effects of different dental materials and endodontics sealers (12).

The cytotoxicity of epoxy resin-based sealers has been previously studied using various cell types (12-15), as well as the cytotoxicity of Epiphany $(16,17)$. However, few investigations have been developed to study the effect of these endodontic sealers on macrophages $(18,19)$. Macrophages play an essential role in the immune response of the host to inflammatory and infectious processes, as well as in the reparative process. At the level of periapical tissues macrophages, by phagocytosis and antigen presentation, have a central function in the repair of chronic apical periodontitis. Moreover, macrophage plays an essential role in periapical lesion development by acting as antigenpresenting cell to memory T lymphocytes (20) and is the predominant cells type in periapical chronic inflammatory processes (21). The results of the present study, demonstrating that $\mathrm{AH} 26$ and $\mathrm{AH}$ Plus decreased rat peritoneal macrophages viability, are in good accordance with previous findings showing that resin-based endodontic sealers suppressed substrate adherence capacity and phagocytosis of mouse peritoneal macrophages (4).

In the present study, crude extracts of Epiphany, $\mathrm{AH}$ Plus and AH 26 tested cytotoxic in rat peritoneal macrophages, reducing significantly the viability of rat peritoneal macrophages, killing $51 \%, 81 \%$ and $86 \%$ of cells, respectively. Correa et al. (9), using the same technique and TPH-cells, reported similar results for AH Plus. Donadio et al. (1) have studied the cytotoxicity of RealSeal sealer, another commercially available form of methacrylate based endodontic sealer, in L929 mouse fibroblasts in vitro, comparing it with traditional $\mathrm{AH} 26$. Their results show that freshly mixed RealSeal sealer have lower cytotoxicity than $\mathrm{AH} 26$ sealer.

Miletić et al. (14) reported high cytotoxicity of AH 26 and AH Plus after determining the number of viable cells using a light microscopy, but did not find mutagenicity for AH26 and AH Plus on human lymphocytes in highly controlled conditions in vitro. Cohen et al. (22) demonstrated the cytotoxic effect of both AH 26 and AH Plus using the agar diffusion test. Similar results were obtained by Huang et al. (7) in cultures of rat hepatocytes. The cytotoxicity of AH Plus when tested using an in vitro culture of human gingival fibroblasts was no longer detectable after $4 \mathrm{hr}$, whereas the cytotoxic effect of AH 26 remained at a high level until $5 \mathrm{wk}$ (23).

AH Plus showed a lower effect on cell viability than AH 26. Other properties and advantages of AH Plus are that it is eugenol and paraformaldehyde free, has a rapid setting time, higher radiopacity, improved removability, 
lower solubility and an acceptable biocompatibility (7, 24, 25). Moreover, AH 26 shows oestrogenic effect in vitro whereas AH Plus did not have oestrogenic effect (26).

The present study shows that Epiphany has lower cytotoxic effect on macrophages viability than resin-based sealers. In accordance with these results, cytotoxicity on HeLa cell of freshly mixed Epiphany sealer has been found to be lower than that of freshly mixed AH-Plus (27). Moreover, Epiphany has been found to present better intraosseous biocompatibility than AH Plus (28).

On the contrary, several studies have found disparate results. Lodiené et al. (13) compared the toxicity of methacrylate resin-based root canal sealers with sealers based on epoxy resin and silicone using the MTT assay ([3-4,5-dimethyl thiazol-2-yl]-2,5-diphenyl tetrazolium bromide succinate), which tests for mitochondrial enzyme activity. These authors found that AH Plus were moderately cytotoxic. The in vitro cytotoxicity of AH-plus and Epiphany has been measured using L929 mouse fibroblasts, osteoblastic cells (ROS) 17/2.8 rat osteoblasts, and MC3T3-E1 mouse osteoblasts (29). After 12 weeks of immersion in saline, AH Plus exhibited the cellular succinate dehydrogenase (CSD) activity above control, but Epiphany reduced CSD by $28 \%$ ( $p<0.05$ ). However, histopathological analysis has demonstrated similar satisfactory results in periapical repair after root canal filling with both AH Plus and Epiphany(30).

\section{Conclusions}

Based on the results of this study, it can be concluded that the methacrylate-based endodontic sealer Epiphany showed lower cytotoxicity on macrophages than resinbased sealers. Both AH 26 and AH Plus crude extracts reduced significantly cell viability of macrophages, but AH Plus was less cytotoxic than AH 26. Dilution of elutes of the three materials by tenfold markedly reduced their effects. Root canal obturation must be performed carefully to avoid the leakage of endodontic sealers to periapical tissues, because they could reduce macrophage viability modulating the repair mechanisms and inflammatory reactions in periradicular tissues.

\section{References}

1. Donadio M, Jiang J, He J, Wang I-H, Safavi KE, Zhu Q. Cytotoxicity evaluation of Activ GP and Resilon sealers in vitro. Oral Surg Oral Med Oral Pathol Oral Radiol Endod. 2009;107:e74-e78.

2. Waltimo TM, Boiesen J, Eriksen HM, Ørstavik D. Clinical performance of three endodontic sealers. Oral Surg Oral Med Oral Pathol Oral Radiol Endod. 2001;92:89-92.

3. Bratel J, Jontell M, Dahlgren U, Bergenholtz G. Effects of root canal sealers on immunocompetent cells in vitro and in vivo. Int Endod J. 1998;31:178-88.

4. Brekalo I, Pezelj-Ribarić S, Abram M, Ahel V. Effect of root canal sealers on mouse peritoneal macrophage functions. Folia Microbiol (Praha). 2007;52:95-8.

5. Segura JJ, Jiménez-Rubio A, Guerrero JM, Calvo JR, Feito JJ. Effect, in vitro, of Tifell (formocresol-eugenol) on macrophage ad- hesion. Int Endod J. 1998;31:112-16

6. Zmener O. Tissue response to a new methacrylate-based root canal sealer: preliminary observations in the subcutaneous connective tissue of rats. J Endod. 2004;30:348-51.

7. Huang TH, Lii CK, Chou MY, Kao CT. Lactate dehydrogenase leakage of hepatocytes with AH 26 and AH Plus sealer treatments. J Endod. 2000;26:509-11.

8. Uyanik MO, Nagas E, Cubukcu HE, Dagli F, Cehreli ZC. Surface porosity of hand-mixed, syringe-mixed and encapsulated set endodontic sealers. Oral Surg Oral Med Oral Pathol Oral Radiol Endod. 2010;109:e117-e122.

9. Correa GTB, Veranio GAC, Silva LE, Hirata R, Coil JM, Scelza MFZ. Cytotoxicity evaluation of two root canal sealers and a commercial calcium hydroxide paste on THP1 cell line by Trypan Blue assay. J Appl Oral Sci. 2009;17:457-61.

10. Scelza MFZ, Oliveira LRL, Carvalho FB, Faria SCR. In vitro evaluation of macrophage viability after incubation in orange oil, eucalyptol and chloroform. Oral Surg Oral Med Oral Pathol Oral Radiol Endod. 2006;102: 24-7.

11. Van Bezooijen C, Van Noord M, Knook D. The viability of parenchymal liver cells isolated from young and old rats. Mech Ageing Dev. 1974;43:107-19.

12. Brzovic V, Miletic I, Zeljezic D, Mladinic M, Kasuba V, Ramic $\mathrm{S}$, Anic I. In vitro genotoxicity of root canal sealers. Int Endod J. 2009;42:253-63.

13. Lodienė G, Morisbak E, Bruzell E, Ørstavik D. Toxicity evaluation of root canal sealers in vitro. Int Endod J. 2008;41:72-7.

14. Miletić I, Anić I, Karlović Z, Maršan T, Pezelj-Ribarić S, Osmak M. Cytotoxic effect of four root filling materials. Endod Dent Traumatol. 2000;16:287-90.

15. Miletić I, Jukić S, Anić I, Zeljezić D, Garaj-Vrhovac V, Osmak M. Examination of cytotoxicity and mutagenicity of AH26 and AH Plus sealers. Int Endod J. 2003;36:330-5.

16. Camargo CH, Camargo SE, Valera MC, Hiller KA, Schmalz G, Schweikl H. The induction of cytotoxicity, oxidative stress, and genotoxicity by root canal sealers in mammalian cells. Oral Surg Oral Med Oral Pathol Oral Radiol Endod. 2009;108:952-60.

17. Heitman EP, Joyce AP, McPherson JC 3rd, Roberts S, Chuang A. An in vitro evaluation of the growth of human periodontal ligament fibroblasts after exposure to a methacrylate-based endodontic sealer. J Endod. 2008;34:186-9.

18. Queiroz CE, Soares JA, Leonardo Rde T, Carlos IZ, Dinelli W. Evaluation of cytotoxicity of two endodontic cements in a macrophage culture. J Appl Oral Sci. 2005;13:237-42.

19. de Campos-Pinto MM, de Oliveira DA, Versiani MA, Silva-Sousa YT, de Sousa-Neto MD, da Cruz Perez DE. Assessment of the biocompatibility of Epiphany root canal sealer in rat subcutaneous tissues. Oral Surg Oral Med Oral Pathol Oral Radiol Endod. 2008; 105:e77-81.

20. Kaneko T, Okiji T, Kan L, Takagi M, Suda H. Ultrastructural analysis of MHC class II molecule-expressing cells in experimentally induced periapical lesions in the rat. J Endod. 2001;27:337-42.

21. Metzger Z. Macrophages in periapical lesions. Endod Dent Traumatol. 2000;16:1-8.

22. Cohen BI, Pagnillo MK, Musikant BL, Deutsch AS. An in vitro study of the cytotoxicity of two root canal sealers. J Endod. 2000;26:228-30.

23. Azar NG, Heidari M, Bahrami ZS, Shokri F. In vitro cytotoxicity of a new epoxy resin root canal sealer. J Endod 2000;26:462-5.

24. Almeida de WA, Leonardo MR, Tanomaru filho M, Silva LA. Evaluation of apical sealing of three endodontic sealers. Int Endod J. 2000;33:25-7.

25. Whitworth JM, Boursin EM. Dissolution of root canal sealer cements in volatile solvents. Int Endod J. 2000;33:19-24.

26. Pulgar R, Segura-Egea JJ, Fernández MF, Serna A, Olea N. The effect of AH 26 and AH Plus on MCF-7 breast cancer cells proliferation in vitro. Int Endod J. 2002;35:551-56.

27. Merdad K, Pascon AE, Kulkarni G, Santerre P, Friedman S. Shortterm cytotoxicity assessment of components of the epiphany resin- 
percha obturating system by indirect and direct contact millipore filter assays. J Endod. 2007;33:24-7.

28. Sousa CJ, Montes CR, Pascon EA, Loyola AM, Versiani MA. Comparison of the intraosseous biocompatibility of AH Plus, EndoREZ, and Epiphany root canal sealers. J Endod. 2006; 32:65662.

29. Brackett MG, Messer RL, Lockwood PE, Bryan TE, Lewis JB, Bouillaguet S, Wataha JC. Cytotoxic response of three cell lines exposed in vitro to dental endodontic sealers. J Biomed Mater Res B Appl Biomater. 2010;95:380-6.

30. Tanomaru-Filho M, Tanomaru JM, Leonardo MR, da Silva LA. Periapical repair after root canal filling with different root canal sealers. Braz Dent J. 2009;20:389-95. 